\title{
Изменение поглотительной способности почв по элементам рельефа балочных водосборов ЦЧР
}

\author{
(C) 2020 Девятова Т.А., Божко С.Н., Горбунова Ю.С. \\ ФГБОУ ВО «Воронежский государственный университет», Воронеж
}

Поступила в редакцию 12.03.2020 г.

DOI: $10.17308 /$ sorpchrom.2020.20/2875

Работа посвящена изучению особенностей состава почвенного поглощающего комплекса (ППК) по элементам рельефа балочного водосбора. Целью работы является выявление зависимости ППК от степени развития и характера водной эрозии и аккумуляции. Для достижения поставленной цели был решен ряд задач: проведение площадной почвенно-эрозионной съемки балочного водосбора; определение физико-химических и физических свойств почв по ГОСТированным и общепринятым методикам; сравнительный анализ поглотительных свойств почв по элементам рельефа балочного водосбора. Высокая степень эродированности территории определяет актуальность исследования поглотительных свойств почв, подверженных смыву и намыву. Объектом исследования являются почвы водосборной площади балки «Лог Репный». Согласно почвенно-эрозионному районированию Воронежской области объект исследования расположен в Семилукско-Нижнедевицком районе.

Наблюдалось обеднение всего профиля почв водораздельных склонов и берега балки илистой фракцией за счет влияния эрозии почв и денудации. На днище балки было зафиксировано обогащение верхней части почвенного профиля илистой фракцией под влиянием аккумуляции почвенного материала, смываемого с вышележащих склонов. Поглотительная способность почв различных элементов рельефа водосборной площади балки «Лог Репный» может быть охарактеризована с помощью величины суммы поглощенных оснований. Наибольшая сумма поглощенных оснований наблюдалась на водораздельном плато (15.73 ммоль/100 г почвы). На берегу балки в условиях влияния процесса денудации зафиксировано уменьшение суммы поглощенных оснований в 2.5 раза. На днище балки в зоне преимущественной аккумуляции смываемого со склонов почвенного материала сумма поглощенных оснований была ниже, чем на водоразделе в 1.4 раза. Это связано с различным содержанием илистой фракции в этих почвах. Так, в почвах водоразделов илистая фракция составляла 24.8\%, на берегу балки ее содержание было в 2.5 раза ниже, а на днище балки вновь возрастало до $22.4 \%$. Установлена зависимость суммы поглощенных оснований почв от перераспределения илистой фракции под влиянием эрозии и аккумуляции почв.

Ключевые слова: почвенный поглощающий комплекс, смытые почвы, водосборная площадь балки, степень насыщенности почв основаниями.

\section{Введение}

Почвенные процессы оказывают существенное влияние на состояние не только экосистем, но и биосферы в целом [1]. Поглотительная способность почв - одно из ее важнейших свойств, в значительной степени определяющее агрономическую ценность. Обменной поглотительной способностью называется свойство почвы поглощать различные ионы из растворов, выделяя при этом эквивалентные количества ионов компенсирующего слоя, находящегося на поверхности коллоидных частиц, ммоль на 100 г почвы. Эта способность обусловлена составом почвенного поглощающего комплекса (ППК) и строением почвенных коллоидов. В основном поглощаются обменные катионы, так как преобладают коллоиды с отрицательным зарядом. 
Наиболее существенным механизмом обменной поглотительной способности является сорбция. Почва - очень сложный полифункциональный сорбент, на котором одно и то же вещество или ион может сорбироваться одновременно по нескольким типам взаимодействия. Сорбционная емкость почв - максимальное количество вещества, способное сорбироваться почвой. Ввиду полифункциональности почвы как сорбента ее сорбционная емкость неодинакова к различным веществам, включая ионы. Сорбция различных веществ может идти параллельно по разным видам поглощения (обменная и необменная сорбция, комплексообразование и т.д.). Основным сорбентом почвы является ее илистая фракция $(<0.001 \mathrm{mм})$, в составе которой ведущая роль принадлежит коллоидам (0.2-0.001 мкм). С ростом $\mathrm{pH}$ возрастает емкость катионного обмена. Сорбционная емкость в почве может достигать больших значений и неодинакова для разных веществ, способных к осадочному поглощению за счет растворения почвенных соединений [2].

Изменение сорбционной емкости почв в зависимости от элемента рельефа можно проследить по пространственной динамике степени насыщенности почв основаниями, суммы поглощенных оснований и емкости катионного обмена. Большое влияние оказывают на сорбцию катионов почвой гранулометрический состав и реакция почвенной среды.

Свойства эродированных почв достаточно хорошо изучены [3-10]. Свойства почв склонов балок охарактеризованы в ряде работ [11-14]. Изменению поглотительной способности почв в зависимости от степени эродированности почв по различным формам рельефа не уделялось достаточного внимания.

Различные почвы существенно отличаются друг от друга по составу катионов, находящихся в обменном состоянии. Состав обменных катионов зависит от типа почвообразования, состава материнской породы, иногда от состава грунтовых вод. В черноземных почвах обменные катионы представлены главным образом $\mathrm{Ca}^{2+}$ и $\mathrm{Mg}^{2+}$, незначительную долю в гумусовых горизонтах составляют ионы $\mathrm{H}^{+}$. Состав и количество поглощенных катионов оказывают большое влияние на физические и химические свойства почв. Так, $\mathrm{Ca}^{2+}$, являясь хорошим коагулятором, способствуют свертыванию почвенных коллоидов и образованию водопрочной структуры. Поглощенный $\mathrm{Mg}^{2+}$ при небольшом содержании (до $15 \%$ емкости катионного обмена) не оказывает негативного влияния на свойства почвы.

Целью работы является выявление зависимости ППК от степени развития и характера водной эрозии и аккумуляции по элементам рельефа балочного водосбора. Для достижения поставленной цели был решен ряд задач: проведение площадной почвенно-эрозионной съемки балочного водосбора; определение физикохимических и физических свойств почв по ГОСТированным и общепринятым методикам; сравнительный анализ поглотительных свойств почв по элементам рельефа балочного водосбора.

\section{Экспериментальная часть}

Объектом исследования являются почвы водосборной площади балки «Лог Репный». Согласно почвенно-эрозионному районированию Воронежской области объект исследования расположен в Семилукско-Нижнедевицком районе, в котором смытые почвы занимают 19\% территории, почвы балочных склонов $-6.8 \%$, почвы днищ балок $-3.8 \%$, овраги - $1.3 \%[15,16]$.

При проведении площадной почвенно-эрозионной съемки был заложен 51 основной разрез, 31 из них с отбором образцов. Кроме того, было заложено 112 полуям, 65 прикопок и 219 точек бурения. Почвенные образцы отбирались из генетиче- 
ских горизонтов почв [17]. По общепринятым и ГОСТированым методикам были проведены следующие виды анализов: гранулометрический состав методом Качинского; $\mathrm{pH}$ водной вытяжки по методу ЦИНАО; сумма поглощенных оснований по методу Каппена, поглощенный кальций и магний; определение гидролитической кислотности почв по Каппену в модификации ЦИНАО [18-21].

\section{Обсуждение результатов}

На водораздельном плато и склонах юго-западной экспозиции балки «Лог Репный» почвообразующими породами являются средние и тяжелые суглинки перегляциальные, подстилаемые мелами туронского яруса. В нижней части склона эти суглинки подстилаются песками разнозернистыми сеноман-альбского возраста. В средней и нижней части берега балки почвообразующими породами являются пески мелко- и среднезернистые сеноман-альбского яруса и пески крупнозернистые аптского возраста. На днище балки почвы формируются на балочном аллювии, подстилаемом верхнедевонской глиной.

По гранулометрическому составу почвы водораздельного плато, склонов югозападной экспозиции и днища балки относятся к среднесуглинистым. На водораздельном плато преобладает иловатая фракция (24.8\%) (рис. 1, табл.). В нижней части профиля почвы происходит утяжеление гранулометрического состава. Это объясняется нарастающим влиянием материнских почвообразующих пород тяжелого состава.

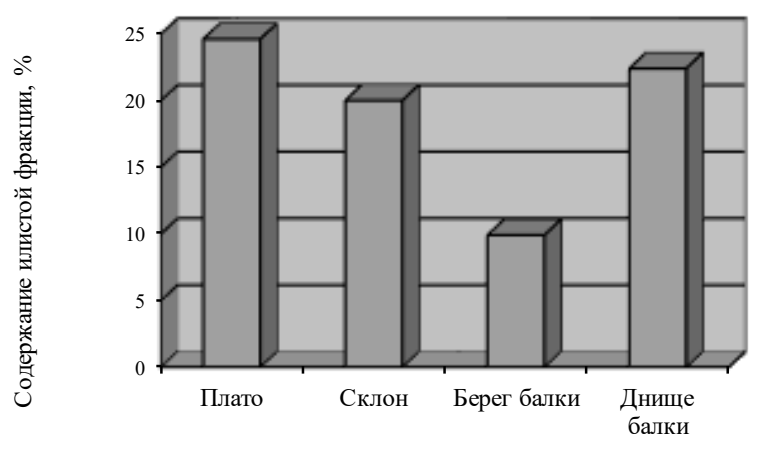

Рис. 1. Изменение содержания илистой фракции в почвах по элементам рельефа балочного водосбора
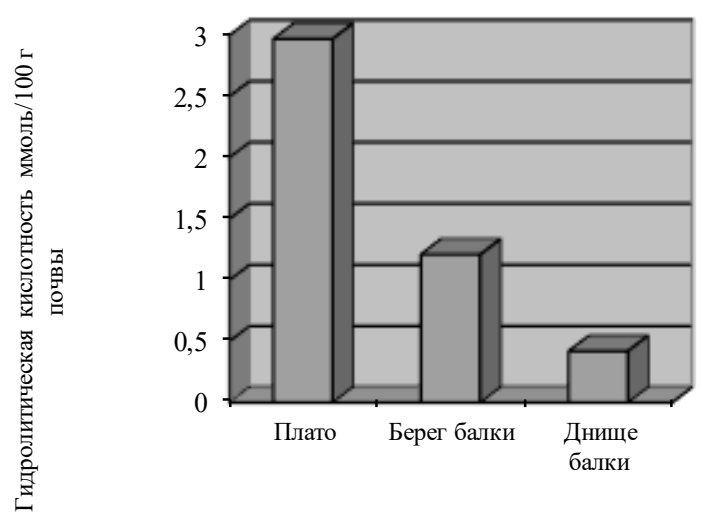

Рис. 2. Изменение гидролитической кислотности в верхнем горизонте почв по элементам рельефа балочного водосбора

На склоне почвы также относятся к среднесуглинистым, но вниз по профилю почвы происходит уменьшение содержания иловатой фракции за счет увеличения содержания песка. Это объясняется более легким гранулометрическим составом подстилающих горных пород.

Почвы берега балки этой экспозиции являются легкосуглинистыми в верхней части профиля и супесчаными в остальной части профиля. Это обуславливается формированием почв на песчаных горных породах. На склоне и берегу балки в почве преобладают фракции песка и крупной пыли. 
Таблица. Физико-химические и химические свойства почв по элементам рельефа балочного водосбора

\begin{tabular}{|c|c|c|c|c|c|}
\hline \multirow[t]{2}{*}{$\begin{array}{l}\text { Глубина, } \\
\text { см }\end{array}$} & pН водной & $\begin{array}{c}\text { Гидроли- } \\
\text { тическая } \\
\text { кислотность }\end{array}$ & $\begin{array}{l}\text { Сумма пог- } \\
\text { лощенных } \\
\text { оснований }\end{array}$ & \multirow{2}{*}{$\begin{array}{c}\text { Степень насы- } \\
\text { щенности } \\
\text { основаниями, } \\
\%\end{array}$} & \multirow[t]{2}{*}{$\begin{array}{c}\text { Илистая } \\
\text { фракция } \\
(<0.001), \%\end{array}$} \\
\hline & & \multicolumn{2}{|c|}{ ммоль/100 г почвы } & & \\
\hline \multicolumn{6}{|c|}{$\begin{array}{l}\text { Чернозем типичный мощный среднегумусный среднесуглинистый; } \\
\text { водораздельное плато; зона отсутствия эрозии и аккумуляции }\end{array}$} \\
\hline $0-22$ & 6.39 & 2.97 & 15.73 & 91.4 & 24.8 \\
\hline $29-39$ & 6.48 & 2.13 & 15.29 & 93.5 & 25.3 \\
\hline $60-70$ & 7.07 & 0.82 & 17.31 & 97.7 & 25.4 \\
\hline $89-99$ & 8.16 & - & - & - & 18.1 \\
\hline $109-119$ & 8.28 & - & - & - & 22.7 \\
\hline $140-150$ & 8.31 & - & - & - & 24.4 \\
\hline \multicolumn{6}{|c|}{$\begin{array}{l}\text { Чернозем делювиально-денудационный карбонатный неполноразвитый маломощный ма- } \\
\text { логумусный среднесуглинистый; средняя часть склона; зона преобладания эрозии }\end{array}$} \\
\hline $15-25$ & 8.20 & - & - & - & 20.0 \\
\hline $39-49$ & 8.19 & - & - & - & 20.8 \\
\hline $53-63$ & 8.26 & - & - & - & 20.8 \\
\hline $78-88$ & 8.26 & - & - & - & 11.0 \\
\hline $101-111$ & 8.50 & - & - & - & 9.1 \\
\hline \multicolumn{6}{|c|}{$\begin{array}{c}\text { Слаборазвитая черноземовидная делювиально-денудационная выщелоченная легкосугли- } \\
\text { нистая почва; берега балки; зона преимущественной денудации }\end{array}$} \\
\hline $5-15$ & 6.71 & 1.21 & 6.37 & 91.3 & 9.9 \\
\hline $16-26$ & 6.30 & 1.02 & 5.12 & 90.9 & 2.3 \\
\hline $36-46$ & 6.36 & 1.00 & 3.43 & 87.3 & 2.6 \\
\hline $100-110$ & 6.41 & 0.99 & 2.62 & 84.1 & 2.8 \\
\hline \multicolumn{6}{|c|}{$\begin{array}{c}\text { Черноземная аллювиально-делювиальная выщелоченная сверхмощная среднегумусная } \\
\text { среднесуглинистая почва; днище балки; зона преимущественной аккумуляции }\end{array}$} \\
\hline $55-65$ & 7.02 & 0.42 & 11.35 & 98.2 & 22.4 \\
\hline $121-131$ & 5.89 & 1.25 & 12.63 & 95.3 & 21.8 \\
\hline $178-188$ & 6.30 & 1.24 & 14.81 & 96.0 & 22.9 \\
\hline $272-282$ & 7.28 & - & - & - & 22.1 \\
\hline $288-298$ & 7.79 & - & - & - & 18.1 \\
\hline
\end{tabular}

На днище балки почвы являются среднесуглинистыми по всему профилю. В верхней части почвенного профиля преобладает фракция ила (22.4\%). В нижних горизонтах почв происходит уменьшение содержания фракции ила за счет увеличения содержания песчаной фракции.

Таким образом, наблюдается обеднение всего профиля почв водораздельных склонов и берега балки илистой фракцией за счет влияния эрозии почв и денудации. Смена почвообразующих пород объясняет облегчение гранулометрического состава на берегу балки. На днище балки зафиксировано обогащение верхней части почвенного профиля илистой фракцией под влиянием аккумуляции почвенного материала, смываемого с вышележащих склонов.

Установлено изменение реакции почвенной среды по элементам рельефа балочного водосбора «Лога Репного». На водораздельном плато в зоне отсутствия

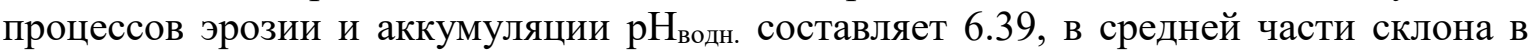
зоне преобладающей эрозии -8.20 , на берегу балки в зоне преимущественной денудации - 6.71, на днище балки в зоне преимущественной аккумуляции - 7.02 (табл.). На водораздельном плато при отсутствии эрозии влияние карбонатности почвообразующих пород проявляется в нарастании щелочности реакции почвенной среды в 
нижней части почвенного профиля. В верхней части профиля этих почв наблюдается слабокислая реакция среды. В средней части склона почвы формировались в условиях эрозии и денудации (геологической эрозии), и влияние карбонатности материнских горных пород проявляется с поверхности почвы в щелочной реакции среды. На берегу балки почвы формируются на песках бескарбонатных и реакция почвенной

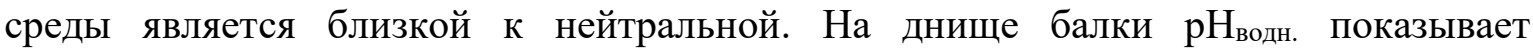
нейтральную реакцию в поверхностном горизонте почв, так как здесь происходит аллювиальное, делювиальное и пролювиальное накопление почвенного материала, смываемого со склонов. С ростом $\mathrm{pH}$ возрастает ионизация функциональных групп гуминовых кислот и глинистых минералов, уменьшается положительный заряд полуторных оксидов и возрастает емкость катионного обмена почв.

Гидролитическая кислотность почв обусловлена взаимодействием почвенных растворов с гидролитически щелочной солью $\left(\mathrm{CH}_{3} \mathrm{COONa}\right)$. При этом происходит эквивалентный обмен $\mathrm{Na}^{+}$на ионы $\mathrm{H}^{+}, \mathrm{Al}^{3+}$, находящиеся в почвенном поглощающем комплексе. Доля участия в ППК обменных катионов водорода и алюминия характеризует ненасыщенность почв основаниями. Наличие гидролитической кислотности характерно для почв, ППК которых обеднен основаниями $\left(\mathrm{Ca}^{2+}, \mathrm{Mg}^{2+}\right.$ и др.). Наибольшая гидролитическая кислотность наблюдалась нами в верхнем горизонте почвы на плато (2.97 ммоль/100 г почвы), в средней части склона она не проявлялась, на берегу балки составляла 1.21 ммоль /100 г, на днище балки 0.42 ммоль/100 г (рис. 2).

Сумма обменных оснований (емкость поглощения) - общее количество катионов, способных к катионному обмену с катионами взаимодействующего почвенного раствора. По нашим наблюдениям сумма поглощенных оснований изменялась от 15.73 ммоль/100 г почвы в верхнем горизонте на водораздельном плато до 6.36 ммоль/100 г на берегу балки (рис. 3). На днище балки этот показатель составлял 11.35 ммоль /100 г. В почвах средней части склона сумма поглощенных оснований не определялась, так как они с поверхности содержат карбонаты.

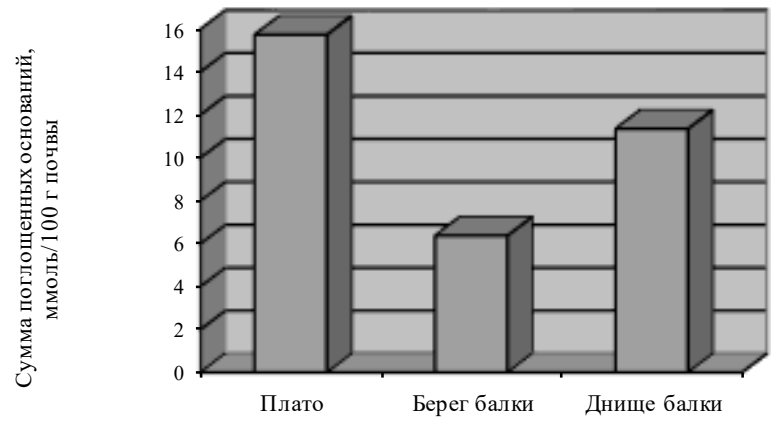

Рис. 3. Изменение суммы поглощенных оснований в верхнем горизонте почв по элементам рельефа балочного водосбора

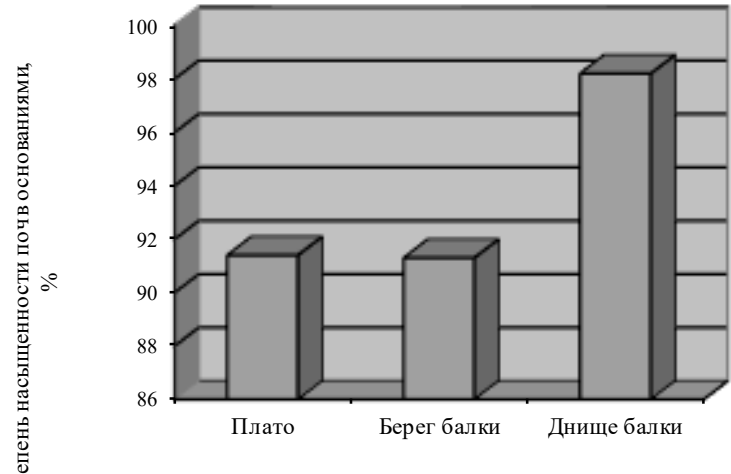

Рис. 4. Изменение степени насыщенности почв основаниями по элементам рельефа балочного водосбора

Степень насыщенности основаниями - это количество обменных оснований, выраженное в процентах от емкости поглощения. Емкость катионного обмена складывается из суммы поглощенных оснований и гидролитической кислотности. По нашим данным степень насыщенности почв основаниями мало отличалась на плато и берегу балки и возрастала на $6.8 \%$ на днище балки (рис. 4 ). 


\section{Заключение}

Поглотительная способность почв различных элементов рельефа водосборной площади балки «Лог Репный» может быть охарактеризована с помощью величины суммы поглощенных оснований. Наибольшая сумма поглощенных оснований наблюдалась на водораздельном плато (15.73 ммоль/100 г почвы). На берегу балки в условиях влияния процесса денудации зафиксировано уменьшение суммы поглощенных оснований в 2.5 раза. На днище балки в зоне преимущественной аккумуляции смываемого со склонов почвенного материала сумма поглощенных оснований была ниже, чем на водоразделе в 1.4 раза. Это связано с различным содержанием илистой фракции в этих почвах. Так, в почвах водоразделов илистая фракция составляла $24.8 \%$, на берегу балки ее содержание было в 2.5 раза ниже, а на днище балки вновь возрастало до $22.4 \%$.

\section{Список литературы}

1. Антропогенная эволюция черноземов / Под ред. А.П. Щербакова. Воронеж. Воронежский государственный университет. 2000. 412 c.

2. Беляев А.Б., Божко С.Н., Одноралов Г.А. Словарь-справочник по агропочвоведению. Воронеж. Центр духовного возрождения Черноземного края. 1999. 393 с.

3. Орлов А.Д., Танасиенко А.А. // Эродированные почвы и повышение их плодородия: Сб. науч. тр. Новосибирск. Наука. 1985. C. $19-26$.

4. Танасиенко А.А. // Почвоведение. 1983. № 4. C. 116-125.

5. Танасиенко А.А. // Эродированные почвы и повышение их плодородия: Сб. науч. тр. Новосибирск. Наука. 1985. С. 33-43.

6. Протасова Н.А., Борзых Л.Г. // Плодородие почв Среднерусской лесостепи и пути его регулирования: Сб. науч. тр. Воронеж. Изд-во Воронеж. ун-та. 1988. С. 23-27.

7. Толчельников Ю.С. Эрозия и дефляция почв. Способы борьбы с ними. М. Агропромиздат. $1990.48 \mathrm{c.}$

8. Танасиенко А.А., Чумбаев А.С., Якутина О.П., Миллер Г.Ф. // Почвоведение. 2013. № 11. C. 1397-1408.

9. Tanasienko A.A., Yakutina O.P., Chumbaev A.S. // Catena. 2011. No 87. pp. 4551.

10. Sepaskhan A.R., Shahabizad V. // Biosystems Engineering. 2010. Vol. 106. No 4.pp. 513-520.

11. Адерихин П.Г., Таллер Е.Б., Гайворон Т.Д. // Агоэкологические проблемы плодородия и охраны почв Средне-Русской лесо- степи: Сб. науч. тр.- Воронеж. 1991. С. 121125.

12. Иванов В.Д., Божко С.Н. // Почвоведение. 2000. № 6. С. 671-682.

13. Buschiazzo D.E., Zobeck T.M. // Earth Surface Landforms. 2008. Vol. 33 (12). pp. 1839-1850.

14. Webb N.P., McGowan H.A., Phinn S.R., McTainsh G.H. // Geomorphology. 2006. Vol. 78 (3-4). pp. 179-200.

15. Долгополов А.Я., Смольянинов В.М., Овчинникова Т.В. Комплексная оценка состояния загрязнения земель в районах с интенсивным антропогенным воздействием на природную среду. Воронеж. Изд-во Воронеж. гос. агро. ун-та. 1997. 126 с.

16. Цыганов М.С., Шепелева В.Г. // Охрана природы Центрально-Черноземной полосы: Сб. науч. тр. Воронеж. Изд-во Воронежского с.-х. института. 1980. Вып. 10. С. 2631.

17. Общесоюзная инструкция по полевым обследованиям и составлению крупномасштабных почвенных карт землепользования. М. Колос. $1973.93 \mathrm{c}$.

18. ГОСТ 26423-85 Почвы. Методы определения удельной электрической проводимости, $\mathrm{pH}$ и плотного остатка водной вытяжки.

19. ГОСТ 27821-88 Почвы. Определение суммы поглощенных оснований по методу Каппена.

20. ГОСТ 26428-85. Почвы. Методы определения кальция и магния в водной вытяжке.

21. ГОСТ 26212-91. Почвы. Определение гидролитической кислотности по методу Каппена в модификации ЦИНАО. 


\title{
Alterations in the absorption capacity of soils depending on the elements of the relief of the ravine catchments of the Central Black Earth Region
}

\author{
(C) 2020 Devyatova T.A., Bozhko S.N., Gorbunova Yu.S. \\ Voronezh State University, Voronezh
}

\begin{abstract}
The article studies the features of the composition of the soil adsorption complex (SAC) with regard to the erosion and accumulation processes. It demonstrates that the adsorption capacity of soils differs depending on the relief of the ravine catchments. The dependency between the amount of absorbed soil bases and the content of silt fraction was determined.

The article studies the composition of the soil adsorption complex depending on the relief of the ravine catchment. The purpose of the study was to determine the dependence of the SAC on the degree of development and nature of water erosion and accumulation. To achieve this goal, the following tasks were performed: conducting a soil-erosion survey of a ravine catchment area; determining the physical and physicochemical properties of soils using GOST and generally accepted methods; performing a comparative analysis of the soil absorption properties depending on the elements of the relief of the ravine catchment. The relevance of the study of the absorption properties of soils subject to washout and deposition is determined by the high degree of erosion of the territory. The object of the study was the soil of the catchment area of the «Log Repny» ravine. According to the soil-erosion zoning of the Voronezh Region, the object of the study is located in the Semiluksky-Nizhnedevitsk District.

The entire soil profile of the watershed slopes and the bank of the ravine was deteriorated by silt fraction due to the influence of soil erosion and denudation. At the bottom of the ravine, the upper part of the soil profile was enriched with silt fraction, which was caused by the accumulation of soil material washed away from the slopes above. The absorption capacity of soils of various elements of the relief of the «Log Repny» catchment area can be characterized by the amount of the absorbed bases. The largest amount of absorbed bases was observed on the inland plateau $(15.73 \mathrm{mmol} / 100 \mathrm{~g}$ of soil). On the bank of the ravine, the amount of absorbed bases was 2.5 times lower, which is accounted for by the denudation process. At the bottom of the ravine, in the zone of primary accumulation of soil material washed off the slopes, the amount of absorbed bases was 1.4 times lower than on the watershed. This happens due to the different content of silt fraction in these soils. Thus, in the soils of watersheds, the silt fraction was $24.8 \%$, on the bank of the ravine its content was 2.5 times lower, and at the bottom of the ravine it grew back to $22.4 \%$. The dependence of the amount of absorbed soil bases on the redistribution of silt fraction under the influence of soil erosion and accumulation was established.
\end{abstract}

Keywords: soil absorption complex, washed away soils, catchment area of the ravine, degree of base saturation of soils.

\section{References}

1. Antropogennaya e'volyuciya chernozemov, Pod red. A.P. Shherbakova, Voronezh, Voronezhskij gosudarstvenny`j universi-tet, 2000, 412 p.

2. Belyaev A.B., Bozhko S.N., Odnoralov G.A., Slovar'-spravochnik po agropochvovedeniyu. Voronezh, Centr duxovnogo vozrozhdeniya Chernozemnogo kraya, 1999, 393 p.

3. Orlov A.D., Tanasienko A.A., E`rodirovanny'e pochvy' i povy'shenie ix plodorodiya, Sb. nauch. tr. Novosibirsk, Nauka, 1985, pp. 19-26.

4. Tanasienko A.A., Pochvovedenie, 1983, No 4, pp. 116-125.
5. Tanasienko A.A., E'rodirovanny'e pochvy' i povy'shenie ix plodorodiya: $\mathrm{Sb}$. nauch. tr. Novosibirsk, Nauka, 1985, pp. 3343.

6. Protasova N.A., Borzy'x L.G., Plodorodie pochv Srednerusskoj lesostepi i puti ego regulirovaniya, $\mathrm{Sb}$. nauch. tr. Vo-ronezh. Izd-vo Voronezh. un-ta, 1988, pp. 23-27.

7. Tolchel'nikov Yu.S., E`roziya i deflyaciya pochv. Sposoby` bor'by`s nim, M., Agropromizdat, 1990, $48 \mathrm{p}$.

8. Tanasienko A.A., Chumbaev A.S., Yakutina O.P., Miller G.F., Pochvovedenie, 2013, No 11, pp. 1397-1408. 
9. Tanasienko A.A., Yakutina O.P., Chumbaev A.S., Catena, 2011, No 87, pp. 4551.

10. Sepaskhan A.R., Shahabizad V., Biosystems Engineering, 2010, Vol. 106, No 4, pp. 513-520.

11. Aderixin P.G., Taller E.B., Gajvo-ron T.D., Agoe kologicheskie problemy' plodorodiya i oxrany' pochv Sredne-Russkoj lesostepi, Sb. nauch. tr., Voronezh, 1991, pp. 121-125.

12. Ivanov V.D., Bozhko S.N., Pochvovedenie, 2000, No 6, pp. 671-682.

13. Buschiazzo D.E., Zobeck T.M., Earth Surface Landforms, 2008, Vol. 33 (12), pp. 1839-1850.

14. Webb N.P., McGowan H.A., Phinn S.R., McTainsh G.H., Geomorphology, 2006, Vol. 78 (3-4), pp. 179-200.

15. Dolgopolov A.Ya., Smol yaninov V.M., Ovchinnikova T.V,. Kompleksnaya ocenka sostoyaniya zagryazneniya zemel' $\mathrm{v}$ rajonax $\mathrm{s}$ intensivny`m antropogenny`m vozdejstviem

Девятова Татьяна Анатольевна - професcop, д.б.н., заведующая кафедрой экологии и земельных ресурсов Воронежского государственного университета, Воронеж

Божко Светлана Николаевна - ст. преподаватель кафедры экологии и земельных ресурсов Воронежского государственного университета, Воронеж

Горбунова Юлия Сергеевна - доцент кафедры экологии и земельных ресурсов Воронежского государственного университета, Воронеж na prirodnuyu sredu, Voro-nezh. Izd-vo, Voronezh. gos. agro. un-ta, 1997, $126 \mathrm{p}$.

16. Cyganov M.S., Shepeleva V.G., Oxrana prirody` Central'no-Chernozemnoj polosy`: Sb. nauch. tr. Voro-nezh, Izd-vo Voronezhskogo s.-x. instituta. 1980, Iss. 10, pp. 26-31.

17. Obshhesoyuznaya instrukciya po polevy'm obsledovaniyam i sostavleniyu krupnomasshtabny'x pochvenny'x kart zemlepol'zovaniya, M. Kolos. 1973, 93 p.

18. GOST 26423-85 Pochvy'. Metody` opredeleniya udel'noj e'lektricheskoj provodimosti, $\mathrm{rN}$ i plotnogo ostatka vodnoj vy`tyazhki.

19. GOST 27821-88 Pochvy`. Opredelenie summy` pogloshhenny'x osnovanij po metodu Kappena.

20. GOST 26428-85. Pochvy`. Metody opredeleniya kal'ciya i magniya $\mathrm{v}$ vodnoj vy`tyazhke.

21. GOST 26212-91. Pochvy`. Opredele-nie gidroliticheskoj kislotnosti po me-todu Kappena $v$ modifikacii CINAO.

Devyatova Tatyana A. - head of the Department of ecology and land resources of the Voronezh State University, the professor, the doctor of biological science, Voronezh

Bozhko Svetlana N. - senior lecturer of the Department of ecology and land resources of the Voronezh State University, the candidate of agricultural sciences, Voronezh, Sveta19691@yandex.ru

Gorbunova Yulia S. - associate professor of the Department of ecology and land resources of the Voronezh State University, the candidate of biological sciences, Voronezh 